\title{
Community Based Survey Methodology for Maternal Healthcare Utilization: Gujarat, India
}

\author{
Kranti Suresh Vora ${ }^{*}$, Kristi Sidney Annerstedt'2, Dileep V. Mavalankar ${ }^{1}$, Nishith B. Dholakia ${ }^{3}$, \\ Sandul Yasobant ${ }^{1}$, Shahin Saiyed ${ }^{1}$, Ashish Upadhyay ${ }^{1}$, Ayesha De Costa ${ }^{2}$
}

\author{
${ }^{1}$ Indian Institute of Public Health, Gandhinagar, India \\ ${ }^{2}$ Public Health Sciences, Karolinska Institutet, Stockholm, Sweden \\ ${ }^{3}$ Department of Health \& Family Welfare, Government of Gujarat, Gandhinagar, India \\ Email: *kvora@iiphg.org
}

How to cite this paper: Vora, K.S., Annerstedt, K.S., Mavalankar, D.V., Dholakia, N.B., Yasobant, S., Saiyed, S., Upadhyay, A. and De Costa, A. (2016) Community Based Survey Methodology for Maternal Healthcare Utilization: Gujarat, India. Health, 8, $1542-1553$

http://dx.doi.org/10.4236/health.2016.814152

Received: October 11, 2016

Accepted: November 14, 2016

Published: November 17, 2016

Copyright $\odot 2016$ by authors and Scientific Research Publishing Inc. This work is licensed under the Creative Commons Attribution International License (CC BY 4.0)

http://creativecommons.org/licenses/by/4.0/ (c) (i) Open Access

\begin{abstract}
Background: About $60 \%$ of institutional births occur in the private sector in Gujarat due to limited availability of obstetricians in the government. Chiranjeevi Yojana (CY), a voucher-like program initiated in 2007, accredits private obstetricians who are reimbursed by the state government to provide free delivery care to eligible women i.e. below poverty line and tribal. One million women have delivered under the CY program yet there are no large community based studies of the program. Methodology of a prospective community study is described here. Methods/Designs: A prospective cohort study was done in 142 villages across 3 districts in Gujarat between July, 2013 and November, 2014. A detailed survey was done by trained researchers to ascertain maternal healthcare information including antenatal, intra-partum and post-partum care, place of delivery, birth outcomes, out of pocket expenses etc. Results: 54,955 households were surveyed. $73 \%$ of all households had poverty documentation. 4274 mothers who delivered in the study period were included. Discussion: This paper is description of the methodology of a large community based survey and household and individual level characteristics. The survey was nested in a larger project to evaluate the CY program in the state of Gujarat.
\end{abstract}

\section{Keywords}

India, Demand Side Financing, Maternal Morality, Chiranjeevi Yojana, Community Based Survey

\section{Introduction}

Major maternal health programs implemented in India during the last decade (20002010) have been noteworthy and consequential in terms of significant expansion of 
maternal and child $(\mathrm{MCH})$ infrastructure. Starting with the Child Survival \& Safe Motherhood (CSSM) program in 1992, Reproductive Child Health I (RCH I) and National Rural Health Mission (NRHM), all had the basic goal to improve the availability of and access to quality health care including maternal and child health care for people especially for those residing in rural areas [1]. NRHM defined the goal of access to maternal health care as availability skilled attendance at birth, timely access to emergency obstetric and newborn care (EmONC), and an efficient referral system [2]. Various strategies implemented were First Referral Units (FRUs), training of various levels of providers for skilled birth attendance, establishing blood storage units and EmOC centres, and demand-side financing programs, namely Janani Suraksha Yojana (JSY), to reduce inequality in maternal health [3]. Recently, public private partnership (PPP) schemes such as Rashtriya Swasthya Bima Yojana (RSBY) and Chiranjeevi Yojana (CY) have been launched in collaboration with private providers for improved access to institutional deliveries and EmONC for poor women as 26\% of the Indian population is living below poverty line [4].

Gujarat is one of the prosperous and urbanized states that have one of the fastest growing economies in India. It is also, one of the most industrialized states with per capita income 1.4 times higher than that of the national average [5]. Despite the economic progress, Gujarat has not fared well on human development indicators such as education, health and gender equality [6]. The slow rate of decline in maternal mortality despite a high proportion of institutional deliveries (more than $80 \%$ as per state government data) may be because of lack of access to Emergency Obstetric Care (EmOC), lack of efficient referral transportation, low quality of care and inadequate postnatal care [7] [8].

One of the reasons for the slow decline of MMR in Gujarat is the severe shortage of obstetricians in the public sector (98\% shortfall) leading to limited access to affordable CEmOC, particularly for poor rural women [9] [10] [11]. On the other hand, there is a strong presence of private obstetricians at the sub district and district levels in Gujarat. In 2007, the state government of Gujarat implemented a pioneering public private partnership approach to engage private providers to offer free delivery services to poor women [12]. The Chiranjeevi Yojana (CY) benefit package provides a cashless delivery to all women who are able to produce proof of belonging to Scheduled Tribes (ST) or Below-Poverty-Line (BPL) categories at a private facility accredited under the program. The accredited private providers are paid by the government for 100 deliveries performed irrespective of the type of delivery i.e. normal delivery or caesarean section or complications handled. This mechanism was to deter private providers from performing medically unnecessary caesarean sections for higher profits. The main objective of the program was to leverage widely available private obstetricians to improve financial and geographic access to skilled birth attendance and CEmOC for poor women in $\mathrm{Gu}$ jarat [13] [14].

Chiranjeevi Yojana has been hailed as one of the innovative demand side financing mechanisms specifically aimed at improving access to health care for vulnerable groups. 
But there is a lack of primary research on the impact of these efforts and a need to evaluate these programs. While, approximately one million women have delivered under the CY program, there have been few research projects to evaluate the public private partnership [12] [15] [16] [17] [18]. Maternal Health India (MATIND), a European Union funded FP7 project, aimed to evaluate the CY program [19], specifically, to study and measure cesarean section (CS) rate, rate of complications treated/handled by the program and to assess patients' perception of care under the program. Further, the project aimed to study the coverage and program participation and financial protection provided by the program and impact of the program on the maternal and neonatal outcomes. This paper describes the methodology and descriptive findings of a prospective community based survey.

\section{Methods}

\subsection{Study Setting}

Gujarat has a population of 60 million and 26 administrative districts. Each district has on an average more than two million people. Districts are divided into $10-12$ blocks (sub-districts) of approximately 100,000 to 200,000 people. Three heterogeneous districts from the western, central and eastern belts of the state, Sabarkantha, Surendranagar and Dahod, were purposefully selected for the study. As indicated in Table 1, these districts had different sub-population compositions i.e. proportions of the eligibility population (scheduled castes and tribes and women living below the poverty line) for the CY program [20].

\subsection{Study Design}

The study adopts a prospective longitudinal study design. Data collection for the community survey was performed from July, 2013 to November, 2014. From each of three districts, two-five blocks were selected.

\subsection{Sampling Framework}

The CY program is targeted to women who belong to the tribal community or live be

Table 1. Demographic characteristics of MATIND ${ }^{\mathrm{a}}$ study districts [25].

\begin{tabular}{cccc}
\hline Indicators & Dahod & Sabarkantha & Surendranagar \\
\hline Populations (2011) & $2,127,086$ & $2,428,589$ & $1,756,268$ \\
Rural Population (\%) & 91 & 85 & 72 \\
Urban Population (\%) & 9 & 15 & 28 \\
BPL Population (\%) & 72 & 33 & 47 \\
ST $^{\mathrm{c}}$ Populations (\%) & 73 & 22 & 1 \\
Literacy Rate (\%) & 59 & 65 & 62 \\
Sex Ratio (Female per 1000 Male) & 990 & 952 & 939 \\
\hline
\end{tabular}

${ }^{a}$ Maternal Health India; ${ }^{b}$ Below Poverty Line, ${ }^{c}$ Scheduled Tribe. 
low the poverty line. As CY providers are not evenly distributed geographically throughout the district, blocks in each district were selected to represent areas where there were no, low (one or two providers) or a high number (more than two per block) of CY providers. Blocks falling into each of these categories were purposively selected in each district. As seen in Figure 1, four, five and three blocks were selected in Sabarkantha, Surendranagar and Dahod districts, respectively.

Selected villages had a population of more than 1000 and less than 2500 people for logistical purposes and to ensure only rural populations were surveyed as access barriers to care are greatest in rural areas. Only villages with BPL populations greater than $40 \%$ were included to ensure maximum coverage of eligible population. Selected villages were scattered all over the block, to geographically represent the block and avoid clustering using Geographical Information System (GIS).

The blocks were selected first and then a list of all the villages for those blocks were compiled using the criteria mentioned above. Information for populations and BPL proportions was obtained from Census 2001 [21]. From the list 142 villages were selected randomly from 12 blocks to cover approximately 300,000 populations.
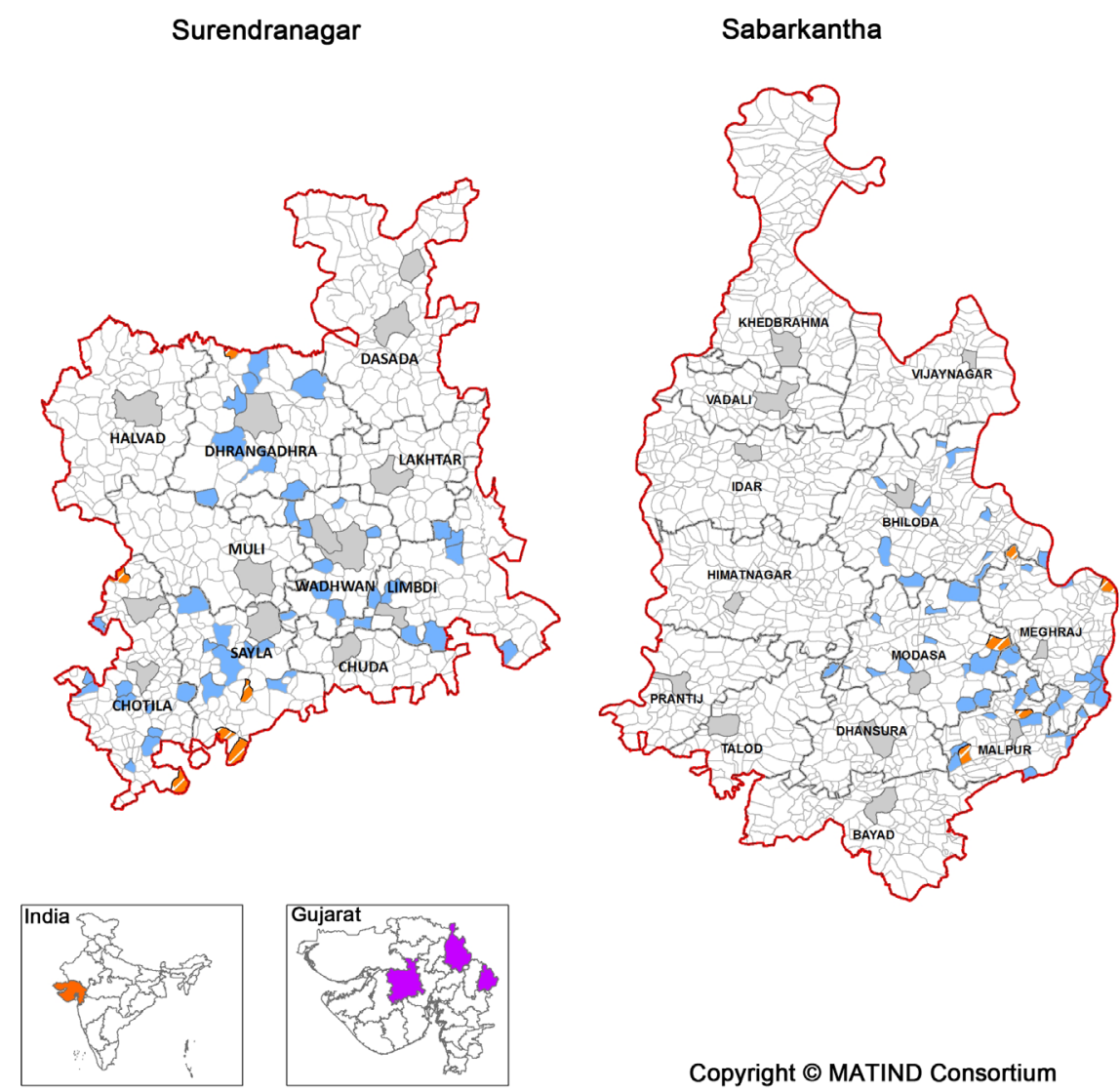

Copyright () MATIND Consortium

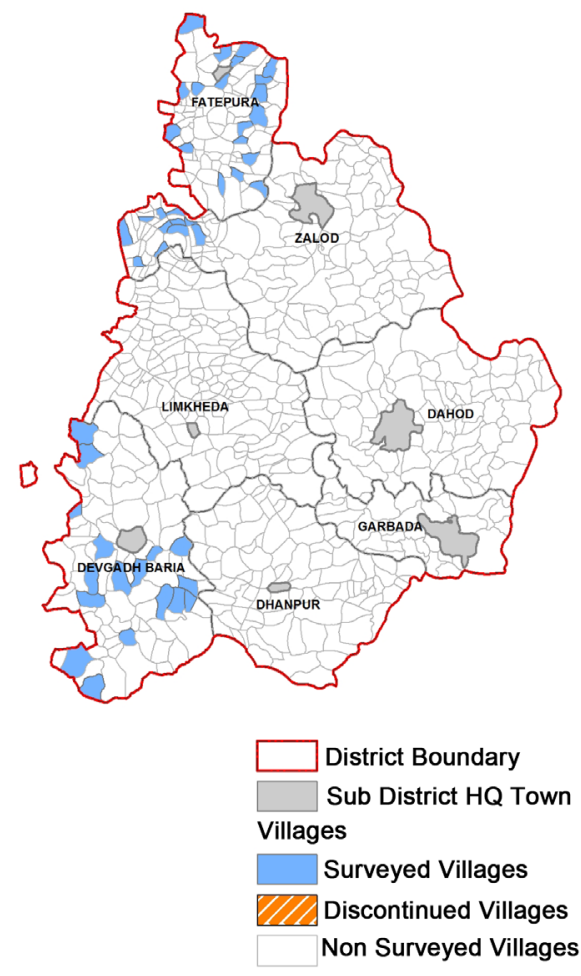

Figure 1. Maps of villages surveyed in MATIND study districts. 


\subsection{Data Collection}

The data collection tools were developed in consultation with all partners including international partners-Karolinska Institutet, Sweden. Project staff and faculties participated in the discussion and previous project study tools were used as basis. After English version was developed, it was translated in local language, Gujarati. Pilot for the data collection methods and tools was done between April, 2013 and June, 2013. Based on observations, data collection tools were modified and strategy for data collection was planned. Data collectors were masters in social work and knew spoken and written Gujarati. District coordinators had knowledge of the districts and rapport with local government staff. Data collectors and district level coordinator were given hands-on training using field mock ups and class room trainings during pilot phase in a block that was not part of the main survey. Data collection points are described in Figure 2.

Data collectors identified mothers who were expected to give birth between July 2013 and October 2014 during house listing visit who were recruited into the prospective cohort. During visit \#2, between $7^{\text {th }}$ and $9^{\text {th }}$ month of pregnancy, information was collected on socio-demographic details, previous pregnancy information, and current antenatal care (ANC) utilization along with household asset and information like type of toilet. At the time of enrolment, key informants such as the community health workers and relatives received information on how to contact the data collector when the mother delivered. Key informants were instructed to contact the data collector within 48 hours of delivery. To ensure delivery information is received in time, the data collector contacted the mother and her relatives a week before expected date of delivery and visited all the households that had a mother due to deliver that month when possible.

The mothers were interviewed at two different time points after delivery; (i) (visit \#3) between 3 - 7 days and (ii) (visit \#4) between the 28 - 35th day post-delivery. Data collectors administered a symptom based checklist to all mothers to ascertain maternal morbidity. Details on type of delivery, expenditure, quality of care and transportation were also collected during visit \#3. Information on neonatal care/outcomes, postnatal care and CY beneficiary status was collected on the last visit (\#4). In the event of a

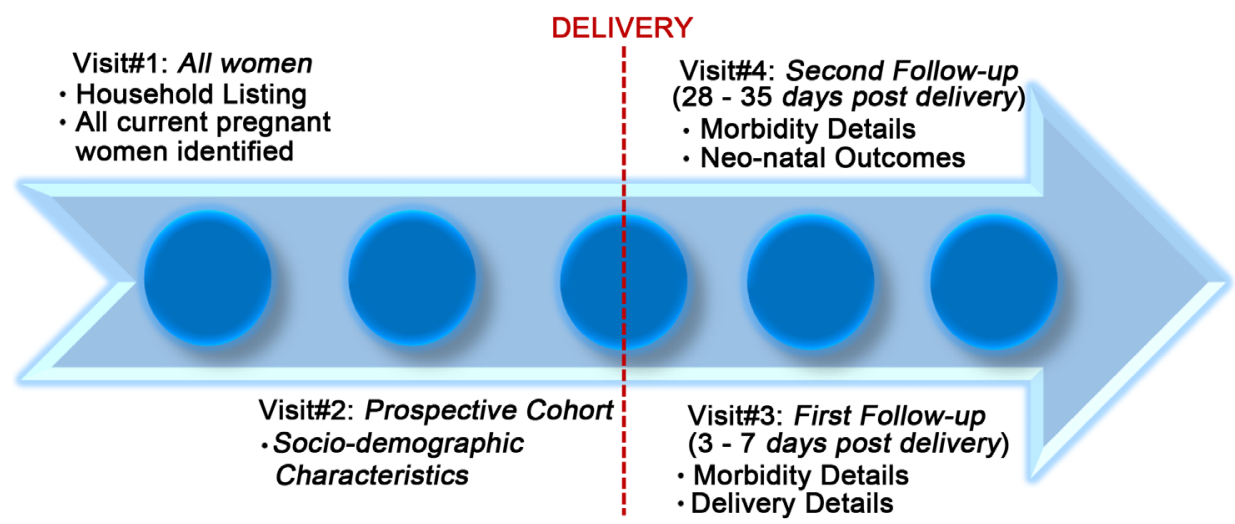

Figure 2. Data collection points for the study. 
maternal death, audit was done using WHO approved community based verbal autopsy tools.

\subsection{Data Quality Assurance Mechanisms}

The Data quality assurance mechanisms were implemented throughout the entire data collection process. During the household listing, a local government official and the district coordinator reviewed the listing to ensure no house was missed. Physical verification was done and number of houses was compared to the latest Census data (2011). All filled questionnaires were reviewed by the district coordinator and then random forms were verified by another team member. After the recruitment of the prospective cohort (pregnant women), an expected date of delivery register was maintained by the data collectors to ensure regular follow up and to minimize lost to follow up.

To ensure anonymity of responders and for identification, all the surveyed households were assigned a Unique Household Identifier (UHI) and mothers were assigned a Unique Personal Identifier (UPI). After submission of forms at state office, all the forms were checked for missing data, consistency and cross verification. To correct inconsistencies in the data, a telephonic-verification system was used by data checking team which directly verified data with mothers.

Study data were managed using a REDCap [22] database. All the forms had blinded double entry to reduce data entry errors. To further ensure data quality; a periodic missing data and outlier check was performed throughout the survey period in the database.

\subsection{Definition of Variables for Descriptive Findings Presented Here}

\section{Dwelling type}

a) Pucca house: The walls consist of burnt bricks, stones (packed with lime or cement), cement concrete, or timber

b) Kutcha-Pucca house: A house that has fixed walls made up of pucca material but roof is made up of the material other than those used for pucca house.

c) Kutcha house: The walls and/or roof are made of material other than those mentioned above, such as un-burnt bricks, bamboos, mud, grass, reeds, thatch, loosely packed stones

2. Age: Age of the woman in total years completed at time of the survey

3. Education: The highest formal class of education completed. It is categorized into 5 categories: No Education, $\leq 5$ class Education, 6 - 9 class Education, 10 - 12 class Education, $>12$ class Education

4. Caste/tribe: Women were divided into four caste groups; scheduled caste (SC), scheduled tribe (ST), other backward castes (OBC) and general. Caste/tribe is a system of Indian social stratification characterized by hereditary status, endogamy, and social barriers sanctioned by custom, law, or religion.

5. Ration card: A government issued document which is in either of following categories. 
a) Below Poverty Line (BPL) status: "BPL" status was determined by documentation such as having a BPL ration card/Antyoday Ann Yojna ration card or name in the BPL list or having a poverty certificate [23].

b) Above poverty line (APL) status: All mothers other than BPL fall in this category.

\subsection{Ethical Considerations}

Ethical permission was granted by Internal Ethics Committee of Indian Institute of Public Health Gandhinagar and Karolinska Institutet. All the forms were anonymized as the participant's name was not recorded. Informed written consent of the participant was taken. If she could not read or write, the consent was read out and a thumb impression of mother was taken on the consent form in the presence of a witness.

\section{Results}

\subsection{Sample of Cohort}

As shown in Figure 3, 54,955 households were surveyed and 69,514 reproductive age women were identified. 4274 women were recruited into the prospective cohort. Among these women, 416 (10\%) were lost to follow up.

The most common reason for loss to follow up was inability to reach the mother in time for the post-delivery visit because of turnover of data collectors and migration of mothers. 3858 mothers were followed up prospectively from their $7^{\text {th }}$ month of pregnancy until 35 days post-delivery. The study sample by district is shown in Table 2.

\subsection{Descriptive Findings (Household Survey)}

As shown in Table 3, more than half of the surveyed households had kutcha-pucca houses while $24 \%$ had either no house or lived in kutcha house. Majority of household heads were males and belonged to Hindu religion. Proportion of households belonging to scheduled tribe (ST) were about $31 \%$ which is similar to the findings from Census

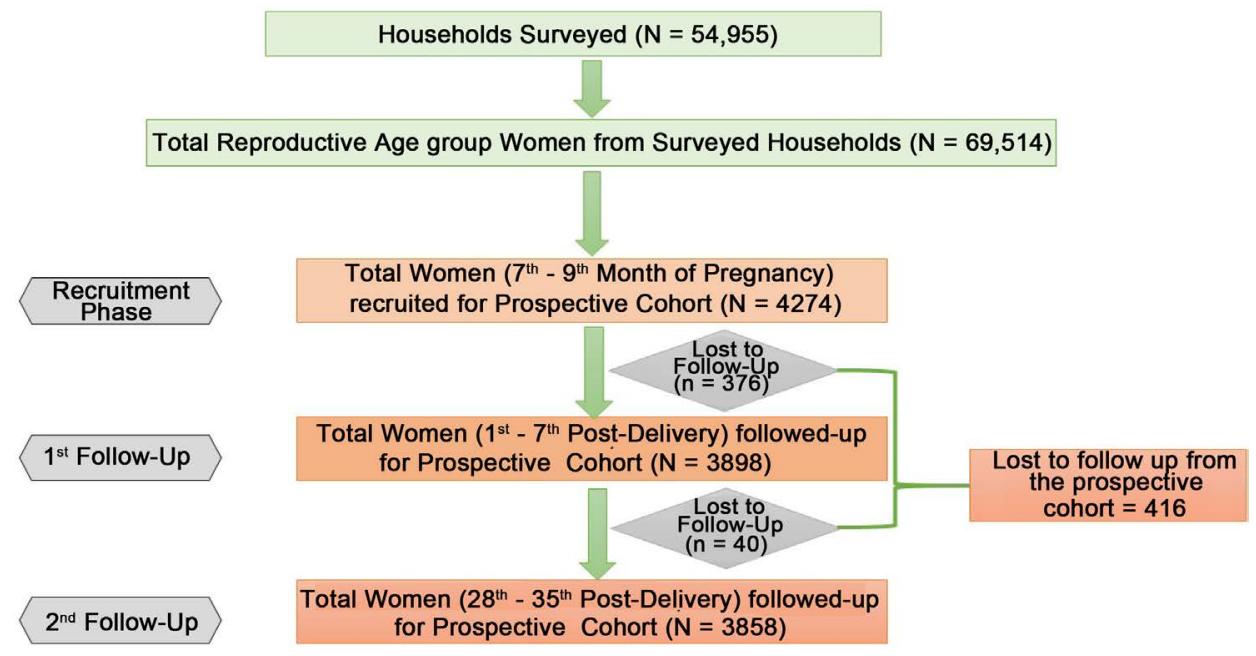

Figure 3. Flow diagram of study participants. 
Table 2. Distribution of total household surveyed, total women in reproductive years, and sample population by district.

\begin{tabular}{cccc}
\hline District Name & Total Households Surveyed & Total Women Age 15 - 49 & Mothers Included in the Study \\
\hline Surendranagar & 20,313 & 24,512 & 1407 \\
Sabarkantha & 16,744 & 19,840 & 1294 \\
Dahod & 17,898 & 25,152 & 1156 \\
Total & 54,955 & 69,504 & 3858 \\
\hline
\end{tabular}

Table 3. Basic household characteristics $(n=54,955)$.

\begin{tabular}{cc}
\hline Variables & Percentages \\
\hline Dwelling Type & 24 \\
Kutcha/No House & 59 \\
Kutcha-Pucca & 17 \\
Pucca & \\
Religion & \\
Hindu & 99 \\
Others & 01 \\
Caste $\quad$ Scheduled Caste & \\
Other Backward Caste & 07 \\
Scheduled Tribe & 57 \\
General & 31 \\
Head of Household & 05 \\
Male & \\
Female & 92 \\
Poverty certificate & 08 \\
Ration Card & 99 \\
Ration Card Type & 59 \\
Above Poverty Line Card & 16 \\
Below Poverty Line Card & \\
Name in Below Poverty Line list & 40 \\
\hline & \\
\hline
\end{tabular}

2011 for the survey villages. About $73 \%$ of all households had poverty documentation. Despite the high proportion of BPL households in the survey, only $15 \%$ had previously availed any maternal health government scheme.

\section{Discussion \& Conclusions}

Although CY has been in existence for about 10 years, there is no effort by the government to systematically evaluate the impact of this program on utilization of maternal health services and improvement in maternal health [24]. As the quality of routinely collected health management information system data is not reliable and not all impact evaluation indicators are collected by this system, it is difficult to attribute change in utilization or maternal health indictors to this innovation [25]. Just like other innova- 
tive programs implemented in India, there was no inbuilt mechanism for the evaluation of the CY program. One impact evaluation of $\mathrm{CY}$ using primary data was performed in 2007, in one pilot district before the program was implemented statewide [13]. A more recent statewide evaluation was done by Mohanan et al. [12] but the sample size per district was very low (50 births per year). Both of these studies were cross-sectional in nature.

As more low and middle income countries (LMIC) are initiating programs to increase institutional delivery to reduce maternal mortality through engaging private sector service providers, it is important to evaluate programs such as CY to benefit from lessons learnt. The learning from CY can be useful to any LMIC looking to implement such programs. This study adds to sparse literature on impact evaluation of such programs. The findings from further analysis of the community based survey data will illustrate level of uptake of the program, quality of care provided and the extent of financial protection. Analysis of socio-demographic characteristics of the mothers and health systems factors such as referral transportation will help shed light on barriers and facilitators for utilization of maternal health services including CY. As neonatal outcomes were also collected along with maternal health indicators including maternal morbidity, the findings from survey data analysis will be useful for program planners and policy makers to improve neonatal outcomes. This is one of the largest prospective maternal morbidity surveys implemented in India.

Although the survey was done in an Indian state of Gujrat, the findings from this study will be widely shared with stakeholders, including donors, collaborative partners, government and the nongovernmental organization sector through reports and seminars at the national as well as international level. These findings will guide program planners and policy makers worldwide to make evidence based decisions. Findings of any evaluation of large scale programs by sampling are inevitably riddled with biases and therefore any conclusions open to debate. Yet, this study is landmark in impact evaluation of engagement of private sector for improving access to maternal health care services and its findings will benefit many.

\section{Methodology Considerations}

The MATIND community based study was done in three diverse districts located in different belts of Gujarat state. The prospective cohort covered more than 300,000 populations and $90 \%$ of the mothers that were recruited were followed up prospectively. The exclusion of 416 mothers who could not be followed up from the prospective cohort does not affect the validity of the findings of the study as these mothers were not different from the mothers in the prospective cohort on almost all the variables except for caste. The 416 mothers were more likely to be from the schedule caste compared to prospective cohort mothers but the distribution across categories of caste was similar among the two groups. As the study purposively oversampled eligible population, it would be feasible to examine uptake of the program among eligible and explore reasons of not participating in the program. This advantage is also a limitation of the metho- 
dology as the findings cannot be generalized. Also, the findings may not be applicable to other districts especially urban districts but as the program was envisaged for poor and socially marginalized women in rural areas, this study findings are vital for examining the impact of the program. For the retrospective study, recall bias can be an issue but the data collection happened within 6-9 months of delivery, hence the problem of recall of important variables such as type of delivery, major complications, CY benefit and cost of delivery is minimal.

Self-reporting of obstetric morbidity is found to be problematic in many countries including India [26] [27]. In the facility base survey done under MATIND in 2012, self-reporting of obstetric morbidity matched significantly with provider reported morbidity in same study districts. As data on various maternal health and service indicators is sparse in India, self-reporting is an accepted way of measuring the same (5).

This paper is description of data collection methods and descriptive findings of community based survey taken for evaluation of CY. Further publications from the data collected will be imperative for future such programs.

\section{Acknowledgements}

Authors are thankful to the Government of Gujarat, Department of Health \& Family Welfare for providing constant support for this study.

Authors are grateful to all the mothers who extended their complete co-operation and MATIND research/support staffs. Authors are thankful to Dr. Sandeep Chauhan, Mr. Hardev Padhiyar, Mr. Vinay Trivedi and Mr. Mehul Bhatia (all MATIND staff) for coordinating the field work. Authors also acknowledge Ms. Bhavna Joshi and Ms. Mitika Patel, Mr Vivek Bhutak and Research Assistants, for their contribution in data management. Ms. Ruchi Bhatt for admin \& finance related works for the project.

\section{Funding}

The research leading to these results has received funding from the European Community's Seventh Framework Programme under grant agreement no. [261304].

\section{Conflict of Interest}

The authors declare that they have no competing interests.

\section{Author Contributions}

KSV, KSA, DVM \& ADC conceptualized the study, KSV, KSA, SY, SS developed study tools and monitoring mechanism for the study. KSV, SY, SS, AU, DVM conducted the study and monitored the data quality assurance during collection and management. KSV, KSA, SY initiated the draft of paper. DVM \& ADC critically reviewed final draft.

\section{References}

[1] National Rural Health Mission (2005) National Rural Health Mission Document (20052012)-Mission Document. Indian Journal of Public Health, 49, 175-183. 
[2] Bhattacharyya, S., Srivastava, A., Avan, B.I. and Graham, W. (2012) Quality Care at Childbirth in the Context of Health Sector Reform Program in India: Contributing Factors, Challenges and Implementation Lesson. iMedPub Journals, 1, 1-8.

[3] National Health Systems Resource Centre, New Delhi, India (2014) NRHM in the Eleventh Five Year Plan (2007-2012): Strengthening Public Health System. http://nhsrcindia.org/NRHM\%20Eleventh\%20Five\%20Year\%20Plan.pdf

[4] Planning Commission, Government of India (2013) Poverty Estimates for 2011-12. http://planningcomission.nic.in/news/pre pov2307.pdf

[5] The Office of the Registrar General \& Census Commissioner, India (2014) States and Union Territories of India. https://en.wikipedia.org/wiki/States and union territories of India

[6] Planning Commission, Governement of India (2014) State-Wise: Population, GSDP, per Capita Income and Growth Rate. http://pbplanning.gov.in/pdf/Statewise\%20GSDP\%20PCI\%20and\%20G.R.pdf

[7] International Institute for Population Sciences (1999) District Level Household and Facility Survey (DLHS-1), 1998-99. http://www.rchiips.org/pdf/rch1/National Report RCH-1.pdf

[8] International Institute for Population Sciences (2008) District Level Household and Facility Survey (DLHS-3) Policy Brief. http://www.rchiips.org/pdf/rch3/policy-brief.pdf

[9] Averting Maternal Death \& Disability Program (2003) Using the UN Process Indicators of Emergnecy Obstetric Services: Averting Maternal Death \& Disability Program. https://www.mailman.columbia.edu/sites/default/files/pdf/usingunindicatorsqa-en.pdf

[10] The United Nations Population Fund (2014) Programme Manager's Planning, Monitoring \& Evaluation Toolkit. Tool Number 6: Programme Indicators. Part II: Indicators for Reducing Maternal Mortality. http://www.unfpa.org/monitoring/toolkit/Tool6 2.doc

[11] WHO, UNICEF \& AMDD (2010) Monitoring Emergency Obstetric Care: A Handbook: World Health Organization. http://whqlibdoc.who.int/publications/2009/9789241547734 eng.pdf

[12] Mohanan, M., Bauhoff, S., La Forgia, G., Babiarz, K.S., Singh, K. and Miller. G. (2014) Effect of Chiranjeevi Yojana on Institutional Deliveries and Neonatal and Maternal Outcomes in Gujarat, India: A Difference-In-Differences Analysis. Bulletin of World Health Organization, 92, 187-194. https:/doi.org/10.2471/BLT.13.124644

[13] Bhat, R., Mavalankar, D.V., Singh, P.V. and Singh. N. (2009) Maternal Healthcare Financing: Gujarat's Chiranjeevi Scheme and Its Beneficiaries. Journal of Health Population \& Nutrition, 27, 249-258. https:/doi.org/10.3329/jhpn.v27i2.3367

[14] Government of Gujarat, Health \& Family Welfare Department (2006) Chiranjeevi Yojana: An Overview. 2006. http://www.gujhealth.gov.in/chirnajivi-yojana-gujarat.htm

[15] Mavalankar, D., Singh, A., Patel, S.R., Desai, A. and Singh, P.V. (2009) Saving Mothers and Newborns through an Innovative Partnership with Private Sector Obstetricians: Chiranjeevi Scheme of Gujarat, India. International Journal of Gynecology and Obstetrics, 107, 271276. https:/doi.org/10.1016/j.ijgo.2009.09.008

[16] Singh, A., Mavalankar, D.V., Bhat, R., Desai, A., Patel, S.R., Singh, P.V., et al. (2009) Providing Skilled Birth Attendants and Emergency Obstetric Care to the Poor through Partnership with Private Sector Obstetricians in Gujarat, India. Bulletin of the World Health Organization, 87, 960-964. https:/doi.org/10.2471/BLT.08.060228

[17] Ng, M., Shanker-Raman, P., Mehta, R., De Costa, A. and Mavalankar, D.V. (2013) Initial Results on the Impact of Chiranjeevi Yojana: A Public-Private Partnership Programme for Maternal Health in Gujarat, India. The Lancet, 381, S98.

https:/doi.org/10.1016/s0140-6736(13)61352-5 
[18] De Costa, A., Vora, K.S., Ryan, K., Raman, P.S., Santacatterina, M. and Mavalankar, D. (2014) The State-Led Large Scale Public Private Partnership 'Chiranjeevi Program' to Increase Access to Institutional Delivery among Poor Women in Gujarat, India: How Has It Done? What Can We Learn? PLoS ONE, 9, e95704.

https:/doi.org/10.1371/journal.pone.0095704

[19] Sidney, K., de Costa, A., Diwan, V., Mavalankar, D.V., Smith, H. and MATIND Study Team (2012) An Evaluation of Two Large Scale Demand Side Financing Programs for Maternal Health in India: The MATIND Study Protocol. BMC Public Health, 12, 1-11.

https:/doi.org/10.1186/1471-2458-12-699

[20] Government of Gujarat (2013) State Profile, Gujrat, India. http://www.gujaratindia.com/

[21] Census of India (2001) Size, Growth Rate and Distribution of Population. Provisional Population Totals. http://censusindia.gov.in/

[22] Harris, P.A., Taylor, R., Thielke, R., Payne, J., Gonzalez, N. and Conde, J.G. (2009) Research Electronic Data Capture (REDCap) - A Metadata-Driven Methodology and Workflow Process for Providing Translational Research Informatics Support. Journal of Biomedical Informatics, 42, 377-381. https:/doi.org/10.1016/j.jbi.2008.08.010

[23] Commissionerate of Rural Development, Gujarat State, India (2014). http://www.ruraldev.gujarat.gov.in/

[24] Mavalankar, D.V., Vora, K.S., Ramani, K.V., Raman, P., Sharma, B. and Upadhyaya, M. (2009) Maternal Health in Gujarat, India: A Case Study. Journal of Health, Population, and Nutrition, 27, 235-248. https:/doi.org/10.3329/jhpn.v27i2.3366

[25] de Costa, A., Vora, K., Schneider, E. and Mavalankar, D. (2015) Gujarat's Chiranjeevi Yojana-A Difficult Assessment in Retrospect. Bulletin of the World Health Organization, 93, 436A-436B. https:/doi.org/10.2471/BLT.14.137745

[26] Ellison, G.T., de Wet, T., Matshidze, K.P. and Cooper, P. (2000) The Reliability and Validity of Self-Reported Reproductive History and Obstetric Morbidity amongst Birth to Ten Mothers in Soweto. Curationis, 23, 76-80. https:/doi.org/10.4102/curationis.v23i4.753

[27] Sloan, N.L., Amoaful, E., Arthur, P., Winikoff, B. and Adjei, S. (2001) Validity of Women's Self-Reported Obstetric Complications in Rural Ghana. Journal of Health Population \& Nutrition, 19, 45-51.

\section{Submit or recommend next manuscript to SCIRP and we will provide best service for you:}

Accepting pre-submission inquiries through Email, Facebook, LinkedIn, Twitter, etc.

A wide selection of journals (inclusive of 9 subjects, more than 200 journals)

Providing 24-hour high-quality service

User-friendly online submission system

Fair and swift peer-review system

Efficient typesetting and proofreading procedure

Display of the result of downloads and visits, as well as the number of cited articles

Maximum dissemination of your research work

Submit your manuscript at: http://papersubmission.scirp.org/

Or contact health@scirp.org 